\title{
63rd AALAS National Meeting
}

\section{4-8 NOVEMBER 2012}

Minneapolis Convention Center

Minneapolis, MN

Registered attendees: 3,973

Exhibitors: 280

The Program Committee for the 63rd annual meeting of the American Association for Laboratory Science (AALAS), chaired by Sonja Chou, chose trauma recovery research as a spotlight topic. This theme was reflected in the keynote address by Major General James K. Gilman during the Opening General Session on Sunday, November 4. Major General Gilman discussed recent advances in battlefield medicine and patient care and the role of lab animals in contributing to these advances. The spotlight topic was also highlighted in presentations throughout the conference that focused on working animals (such as dogs trained for military and other service); lab models of radiation syndrome and traumatic injury; and in vitro adjuncts to animal-based trauma research.

Sunday's Opening General Session also featured the presentation of several annual AALAS awards. The Charles A. Griffin Awardthe oldest AALAS award, first presented in 1954-recognizes ethical scientific or technological advancements in humane experimentation or improved animal care practices and was given to Marilyn Brown. The Nathan R. Brewer Lifetime Achievement Award for outstanding lifelong contributions to improving the care, quality and environment of animals used in biologic and medical research was given to Craig Franklin. Craig Fisk received the Joseph J. Garvey Management Award in recognition of his outstanding accomplishments in the administration of programs relating to the care, quality or humane treatment of animals used in biomedical research. The Pravin N. Bhatt Scientific Investigator Award for outstanding scientific accomplishments, established in 1994, was given to Joseph Garner. The George R. Collins Education and Training Award recognizing outstanding contributions to the field of laboratory animal training and education was presented to Denise Ostmeyer. Xiomara Santiago was recognized as Technician of the Year for her contributions to the promotion of laboratory animal care.

Each year, the AALAS national meeting features several special lectures. The first of these took place on Monday morning, November 5. The Charles C. Hunter Lecture pays tribute to the late Dr. Hunter, a former AALAS president known for his dedication to continuing education for laboratory animal technicians. This year's Hunter Lecturer, Peggy Callahan, spoke about her research with captive wolves. The Charles River Ethics and Animal Welfare Lecture, sponsored in part by the Charles River Commitment to Humane Animal

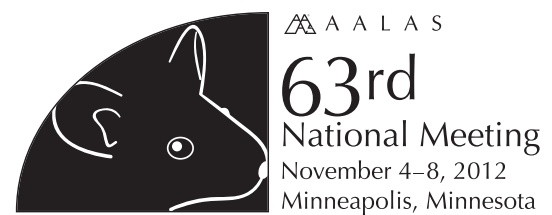

Research through Excellence and Responsibility Program, was given on Tuesday morning, November 6, by Bernard Rollin, who discussed the ethics of animal research. Also on Tuesday morning, the Wallace P. Rowe Lecture, named after the first scientist to undertake systemic studies of viral infections of lab mice, was a presentation by Axel Kornerup Hansen titled "The impact of the gut microbiota on rodent models of human diseases."

AALAS held its General Membership Meeting on Monday, November 5, which included a ceremony introducing the new President. AALAS leadership is a four-year commitment, beginning at the close of each annual meeting. During the first year, officers serve as Vice-President Elect, advancing to Vice President in their second year of service, to President in their third year and finally to Past-President in their last year. In Minneapolis, 2012 AALAS President Kathy Laber passed the gavel to Kim Saunders, 2013 AALAS President. Laber becomes the new Past-President, as Robert Dysko exits the office. Scott Mischler replaces Saunders as Vice President for 2013, and earlier in the year, Cindy Buckmaster was chosen as the Vice President-Elect. Nominations for the 2014 Vice President-Elect were due February 1, 2013.

On Wednesday, November 7, poster awards were given in three topic categories: clinical, husbandry/management and laboratory investigations. First place in the clinical set was awarded to Doreen Kohlert for her poster, "Unanaesthetized sublingual blood collection in rats." Second place went to Kathryn Mullen's poster, "A novel method of oral drug administration for rabbits," and Erica Sheldon won third place with her poster, "Rehabilitation technique after finger fracture in a baboon (Papio anubis)." In the husbandry/management category, "Creation and use of environmental enrichment checksheets" by Denise Molk earned first place and "Pooled fecal floats from colony cages detect Aspiculuris tetraptera and fur mites" by Julie Watson was awarded second place. Third place went to Michelle Wallace-Fields for her poster, "A novel approach to a mopping system to reduce labor and product costs and decrease chemical usage." Finally, in the laboratory investigations area, "Impact of mouse age on fur pluck surveillance of Myocoptes musculinus" by Kelly Rice took first place. The secondplace poster was Amanda Leber's work, "Mucosal cheek pouch tattoos allow repeat assessment of experimentally induced oral tumor development in Syrian hamsters (Mesocrietes auratus)." Shannon Stutler won third place with her poster, "Use of novel telemetry devices to collect individually discernible data sets from socially housed rhesus macaques (Macaca mulatta)." 